\title{
Innovative Geoinformation Systems for the Design of Communication Paths
}

\author{
Yevheniia Ugnenko (D) 1 , Olha Tymchenko (iD) ${ }^{2}$, Elena Uzhviieva (iD ${ }^{3}$, \\ Nataliia Sorochuk (D) ${ }^{4}$, Gintas Viselga (D) ${ }^{*}$ \\ ${ }^{1-4}$ Department of Research and Design of Communication Paths, Geodesy and Land Management, \\ Faculty of Construction, Ukrainian State University of Railway Transport, Kharkiv, Ukraine \\ ${ }^{5}$ Department of Mechanics and Materials Engineering, Faculty of Mechanics, \\ Vilnius Gediminas Technical University, Vilnius, Lithuania
}

Received 4 February 2020; accepted 31 March 2020

\begin{abstract}
The article analyses the volume of passenger traffic from 1990 to 2019 for land, water and air transport. From the materials obtained and the experience of the networks of European and world high-speed railways, goals are set. High-speed lines designed exclusively for passenger traffic. This moment plays an important role in reducing the cost of construction, increasing the market and economic profitability. According to the data from the State Statistics Service of Ukraine, it is possible to calculate the passenger flow based on the known parameters for 2020-2032 in the direction of Kiev-Lviv. The design of high-speed lines should meet general requirements aimed at satisfying the basic characteristics of a high-speed railway system, which works in conjunction with the European High-Speed Railway network. The compatibility of the parameters of high-speed lines with the parameters of traditional lines is part of the operational requirements for the gradual introduction of a network of high-speed railways. Possible scenarios to achieve the required compatibility should cover all subsystems.
\end{abstract}

Keywords: communication path, design, geoinformation system, longitudinal profile, parameters optimization, mathematical model, information technologies.

\section{Introduction}

In recent years the widespread and development of geoinformation systems has made it possible to integrate them into the process of automated design of communication paths. In the present time accumulated native and foreign experience shows that the application of mathematical methods and means of automation and computer technology in the design significantly increases the technical level and quality of the design objects in a significant reduction in the value of construction and dramatically shortens time for development of project.

Automated design proves to be especially effective when, from separate calculations on computers, they proceed to the development and use of automated design systems, in which all stages of design and development work are already connected, starting with the collection, processing and submission of initial design information and finishing with design documentation (Labenko \& Timonin, 2012).

An automated design system is an organizational and technical system consisting of a complex of design automation tools interconnected with the units of the design organization that performs the automation design (Zatserkovnyi et al., 2014).

It is necessary to distinguish between automatic design and automation. In the case of automatic design, the process of receiving, transforming, transmitting information, forming control commands is carried out automatically without the participation of the design engineer. However, in this case, the designer takes direct part in the main stages of the design process: at the stage of preparation of the initial data for the design, and then at the stage of evaluation of the received design decision with the next possible corrections. In the automated design, designed for the design of complex and even unique engineering structures, such as communication paths and structures, the design engineer directly takes part in the process of making a design decision, sending the design process in the right direction.

The main effect of the application of the automated design system arises as a result of the automation of various creative human functions at the early stages of project development, when the most fundamental decisions are made. Creative process of creation by the design engineer with the help of technical means of the automated design system

${ }^{*}$ Corresponding author. E-mail: gintas.viselga@vgtu.lt 
of the mathematical model of the object of construction, operative analysis during this process of merits and shortcomings of the model define a qualitatively new situation in the design. During the dialogue with the computer, the design engineer thoroughly analyzes a large number of variants, optimizes the design decisions, simulates the behavior of the object or its individual elements in time and space and ultimately selects (most often the method of expert evaluation) the best option for further detailed processing.

The purpose of creating an automated design system is (Labenko \& Timonin, 2012; Zatserkovnyi et al., 2014):

- Improving the quality of design objects. For example, the development of projects of communication paths that have a visually smooth route, organically fits into the surrounding landscape and enriches it, provides the best transport and operational indicators;

- Reducing the value of construction of objects and their material capacity. The cost of communication paths and the material capacity of design solutions for system automated design is found to be from 10 to 15 per cent below the corresponding indicators when using traditional technology;

- Reduction of the terms of designing, labor costs and improvement of the quality of project - estimate documentation. In system automated design, the terms of the design and research cycle with corresponding increase of the labour productivity are reduced by an average of $20 \div 25$ per cent and more.

Preparation of project - estimate documentation with the use of automation means ensures the design of the project (explanatory notes, estimates and drawings) with a quality that is not achievable with traditional technology.

The following factors provide the economic effect at designing with the use of the automated design system (Zatserkovnyi et al., 2014):

- Systematic use of automated design tools. The design results for one of the automated design subsystems are automatically used as source information for the next stages of automated design without laborious manual retraining. Becides, the large number of inevitable mistakes is also decisive. Using the system of automated design automates the time consuming and routine operations of traditional technology;

- Creation of new production technology for design and survey works. Designing at the level of the automated design system presupposes the use of qualitatively excellent technology of execution of design and survey works, characterized by systematic, complex, breadth of coverage and exceptional depth of processing;

- Increasing the specialization of the labour. Foreign and native experience in system design convinces in the need for separation of research functions and own design between specialized organizations, equipped with appropriate equipment, research and project organizations, and also in the separation of design functions.

A number of tasks inherent for the systems of automated road design are put forward on geoinformation systems due to their peculiarities.

For example, in the geoinformation system, unlike the system of automated design, a small number of graphic primitives are used: points, lines, polygons, surfaces. This feature of such systems makes it possible to clearly define such spatial operations as the search for objects in a given region, the search for adjacent or intersecting objects, the construction of connections, crossings and differences of polygons, the construction of buffer zones.

Algorithmic methods are widely used in geoinformation systems for storing large volumes of data, quick search of objects, simplification of data for fast output on the screen. This allows the use of geoinformation systems to represent the network of road on electronic small-scale maps, for the analysis of the transport maintenance of the areas, for the receipt of strategic information about the objects of the transport network and the choice of the most acceptable corridor of variation of the projected route for the corresponding digital model of locality (Chepel, 2015; Autodesk, 2020; Sivovolov \& Ivanov, 2008; Credo-Dialogue, 2019).

In geoinformation systems, graphical objects of the same type are transmitted in one layer of graphical data and have the same set of attributes. This feature of geoinformation systems allows to present a layer of graphical data with sets of attributes of objects in the form of a table of relational database, and therefore, to use the corresponding device of databases for the analysis of attributes of graphical objects. The presence of attribute support in geoinformation systems makes it possible to apply them in solving problems of diagnostics, passportization, inventory, cadastre of roads. These features of geoinformation systems make it possible to integrate them with systems of automated design of roads, such systems are becoming more widespread recently.

\section{Overview of the design rules for geometric characteristics of the longitudinal profile}

In substantiating the design regularities of geometric elements of the communication paths, the features of real modes of traffic of vehicles should be taken into account, including:

- Constant and variable speeds of movement;

- Parameters of regularities of uniform deceleration or acceleration;

- The dependence of the clutch coefficients, the coefficients of the longitudinal, cross and vector sums of these forces, and also the indices of the convenience of movement from the characteristics of these modes. 
The plan and longitudinal profile of the route of the communication paths should be designed in compliance with the requirements of spatial smoothness and the harmonious combination of the geometric model of the projected route with the relief of the adjoining terrain in the form of $\mathrm{G} 2$ - smooth polylines and regularity of geometric properties which should provide safety and convenience of modes of movement.

\section{Design rules of Belarus (Gosstandart, 2006)}

The plan and longitudinal profile of roads should be designed on the basis of the conditions of the least restriction and change of speed, safety and comfort of traffic, possibility of reconstruction of the road beyond the limits of perspective period.

In new construction, and if possible during the reconstruction, the route should be designed taking into account the principles of landscape design as a smooth spatial line with the mutual connection of elements of the plan and profile with each other and with the surrounding landscape, with an assessment of their visual perception.

As constituent elements of the plan and the longitudinal profile of the route, the curves should be used as a constant, as well as a variable curvature of a linear or nonlinear function, a also straight lines. As the main constituent element of the road plan, straight lines can be used, as a rule, only during reconstruction.

If the conditions of the terrain do not make it possible to fulfill the conditions of their execution due to the considerable amount of work and the cost of construction, during the justification allows to reduce the design standards to the maximum permissible. The maximum permissible standards are presented in Table 1 (Gosstandart, 2006).

Table 1. The maximum permissible standards

\begin{tabular}{|c|c|c|c|c|}
\hline \multirow{2}{*}{$\begin{array}{c}\text { Calculation } \\
\text { speed, } \mathrm{km} / \mathrm{h}\end{array}$} & $\begin{array}{c}\text { The greatest longitudinal } \\
\text { down-grade, } \%\end{array}$ & \multirow{2}{*}{$\begin{array}{c}\text { The least stop visibility } \\
\text { distance, } \mathrm{m}\end{array}$} & \multicolumn{2}{|c|}{$\begin{array}{c}\text { The smallest radius of curvature in the } \\
\text { longitudinal profile, } \mathrm{m}\end{array}$} \\
\cline { 3 - 5 } & 40 & 350 & 25000 & 8000 \\
\hline 140 & 40 & 250 & 15000 & 6000 \\
\hline 120 & 50 & 160 & 8000 & 4000 \\
\hline 100 & 60 & 100 & 4000 & 2500 \\
\hline 80 & 70 & 60 & 1500 & 1500 \\
\hline 60 & 90 & 40 & 1000 & 1000 \\
\hline 40 & & & & Convex curve \\
\hline
\end{tabular}

\section{Design rules for Germany (Rosavtodor, 2003)}

In order to meet the requirements of traffic safety, to save operating costs and energy, to reduce emissions of harmful substances and to ensure the quality of the movement process, longitudinal down-grades should be as low as possible and not exceed 4 per cent. On the other hand, to reduce interference in the natural landscape and urban environment, to reduce construction cost, longitudinal down-grades should, where possible, be consistent with the terrain. The main characteristics are given in Tables 2-4 (Rosavtodor, 2003).

Table 2. Maximum increment of longitudinal down-grades

\begin{tabular}{|c|c|c|}
\hline \multirow{2}{*}{ Design speed $V e, \mathrm{~km} / \mathrm{h}$} & \multicolumn{2}{|c|}{ Maximum increment of longitudinal down-grades $s_{\max }, \%$, for roads } \\
\cline { 2 - 3 } & group A & categories BI / BII \\
\hline 50 & 9.0 & 12.0 \\
\hline 60 & 8.0 & 10.0 \\
\hline 70 & 7.0 & 8.0 \\
\hline 80 & 6.0 & 7.0 \\
\hline 90 & 5.0 & 6.0 \\
\hline 100 & 4.5 & 5.0 \\
\hline 120 & 4.0 & - \\
\hline
\end{tabular}


Table 3. Radii and minimum radii of convex curves

\begin{tabular}{|c|c|c|}
\hline \multirow{2}{*}{$\begin{array}{c}\text { Design speed } V, \\
\mathrm{~km} / \mathrm{h}\end{array}$} & \multicolumn{2}{|c|}{ Radii of convex curves, $\mathrm{m}$} \\
\cline { 2 - 3 } & $H_{k \cdot \min }\left(\right.$ at $\left.S_{h}\right)$ & $H_{k}$ at $0,5 \cdot S_{u} /$ at $\left.S_{u}\right)$ \\
\hline 50 & 1400 & $7000 / 28200$ \\
\hline 60 & 2400 & $7800 / 30000$ \\
\hline 70 & 3150 & $8600 / 35000$ \\
\hline 80 & 4400 & $10300 / 40000$ \\
\hline 90 & 5700 & $12200 / 48000$ \\
\hline 100 & 8300 & $13000 / 52000$ \\
\hline 120 & 16000 & - \\
\hline
\end{tabular}

Design rules for Ukraine (Ministerstvo regional'nogo rozvitku, budivnictva ta zhitlovo-komunal'nogo gospodarstva Ukraini, 2015, 2008)

The route should be designed as a smooth line in space with the connection of plan elements, longitudinal and cross profiles with each other, with the surrounding landscape and with their influence on the traffic conditions and visual perception of the road.

Table 4. Radii and minimum radii of concave curves

\begin{tabular}{|c|c|}
\hline Design speed $V, \mathrm{~km} / \mathrm{h}$ & The minimum radius of a concave vertical curve $H_{w \min }, \mathrm{m}$ \\
\hline 50 & 500 \\
\hline 60 & 750 \\
\hline 70 & 1000 \\
\hline 80 & 1300 \\
\hline 90 & 2400 \\
\hline 100 & 3800 \\
\hline 120 & 8800 \\
\hline
\end{tabular}

For the elements of the plan and the longitudinal profile, the basic parameters should be assigned as follows (Ministerstvo regional'nogo rozvitku, budivnictva ta zhitlovo-komunal'nogo gospodarstva Ukraini, 2015):

- Longitudinal down-grades;

- Distance of visibility for the condition of stopping of the vehicle;

- Radii of curves in the plane;

- Radii of convex curves in the longitudinal profile;

- Radii of concave curves in the longitudinal profile;

- Length of convex curves in the longitudinal profile;

- The length of the curved curves in the longitudinal profile.

The normative parameters of different countries are shown in Table 5.

Table 5. Summary table of normative parameters of different countries

\begin{tabular}{|l|c|c|c|}
\hline \multicolumn{1}{|c|}{ Country } & Ukraine & Belarus & Germany \\
\hline Normative document & DBN B.2.3-4:2015 & TKP 45-3.03-19-2006 & RAS-Q 2003 \\
\hline The maximum radius of the convex curve, $m$ & 9000 & 8000 & 8300 \\
\hline The maximum radius of the concave curve, $m$ & 2100 & 4000 & 3800 \\
\hline Maximum longitudinal down-grade, $\%$ o & 60 & 50 & 50 \\
\hline
\end{tabular}




\section{Methodological principles for finding the optimal design solution of longitudinal profile}

Before we go directly to the example of applying the method of dynamic programming to optimize the design line of a longitudinal profile, let us first define the criterion of the efficiency of solving a given problem, that is, with its objective function.

Based on the fact that speed, bandwidth, safety and ease of movement depend on the results of its decision, as well as construction, operation and other expenses throughout the life cycle of the road, this task belongs to the class of multicriteria.

For the purpose of simplification, we can proceed from the fact that the necessary level of transport and operating indicators, including speed, bandwidth, safety and convenience of movement, will be ensured in compliance with the normative requirements for such geometric parameters of longitudinal profiles as down-grades, curvature and rate of its change.

The desired geometric and dynamic smoothness of the longitudinal profile should be ensured not at the expense of limiting the minimum lengths of its elements, but at the expense of ensuring the continuity of the curvature $\left(G_{2}\right.$-smoothness) and the permissible rate of its change (Credo-Dialogue, 2019).

The requirement to minimize disposable, construction and long-term operating costs throughout the life cycle of the road should not be understood in the literal sense.

Their savings due to the minimization of the height of the road embankment can lead to increased costs with snow drifts and high risks of traffic jams, deterioration of the water-thermal regime of the road bed and shortening of the service life of pavements, flooding or erosion of sections of roads during floods and deprivation of transport accessibility of entire regions.

The account of these topographic, geological, hydrological, meteorological, ecological, aesthetic and other factors is carried out at the initial stage of longitudinal profile design, including in the process of substantiation of the parameters of the desired contours of the cross profile for design road.

Thus, in the example presented in Figure 1, we show the definition of better variant of the cross profile of the embankment based on the choice of the efficiency criterion.

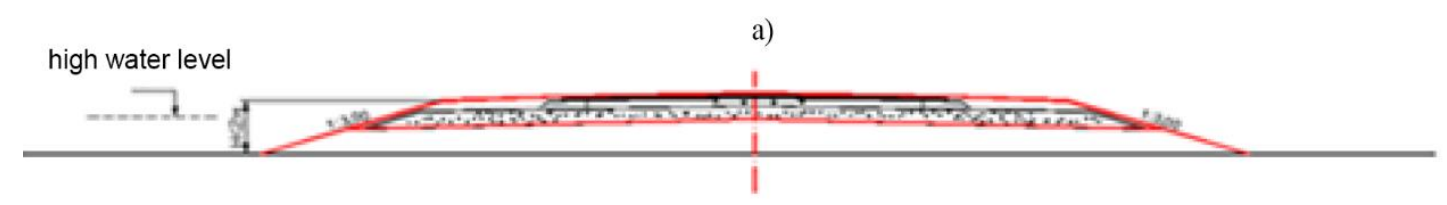

b)

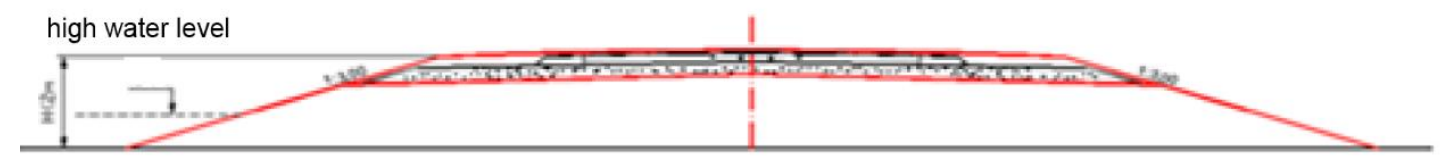

c)

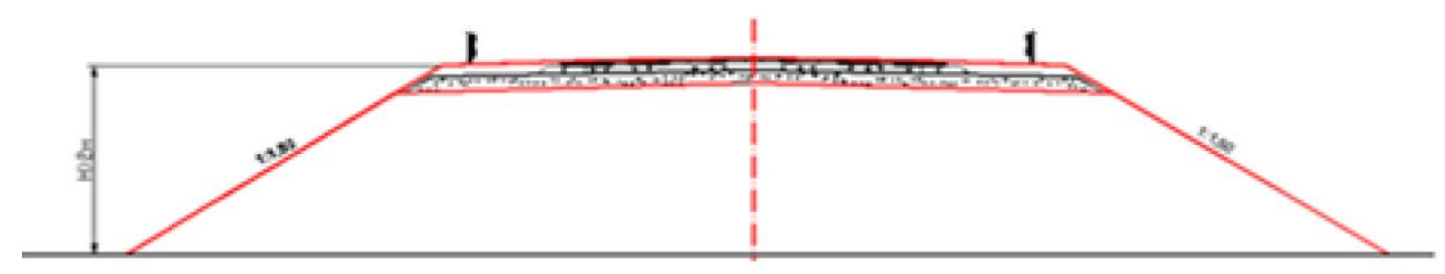

Figure 1. Better variant of the cross profile of the embankment (b), based on the choice of efficiency criterion: a) embankment up to $1 \mathrm{~m}$; b) embankment up to $2 \mathrm{~m}$; c) embankment more than $2 \mathrm{~m}$

A better variant of the cross profile of the roadway excavation, in which it is desired to open the roadway excavation, is presented in Figure 2. 
a)

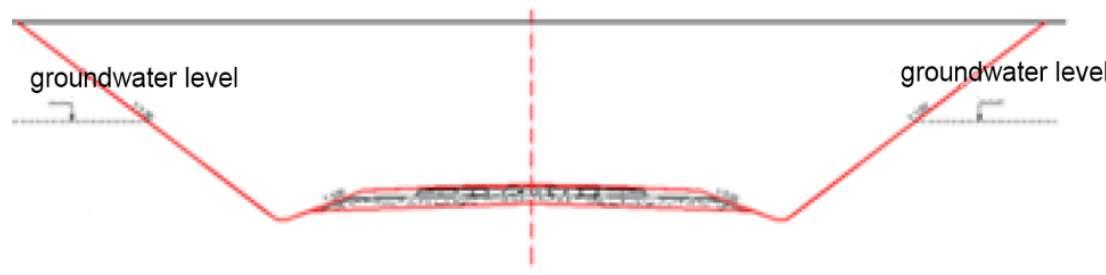

b)

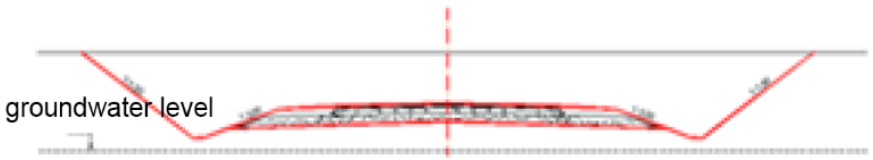

Figure 2. Better variant of the cross profile of the roadway excavation (b): a) deep roadway excavation; b) roadway excavation up to $1 \mathrm{~m}$ deep

Variants of the cross profile on the slopes are presented in Figure 3.

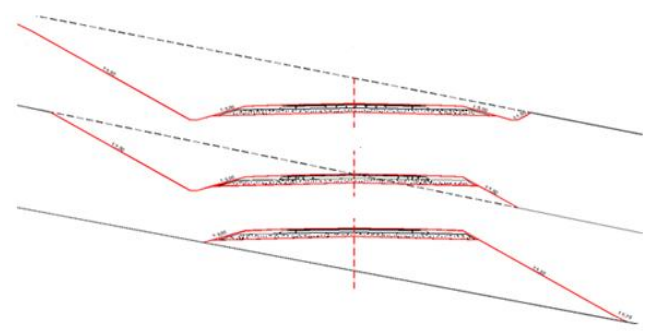

Figure 3. Better variant of the cross profile at the slopes

The minimum height of the embankment in the places of installation of artificial structures is presented in Figure 4.

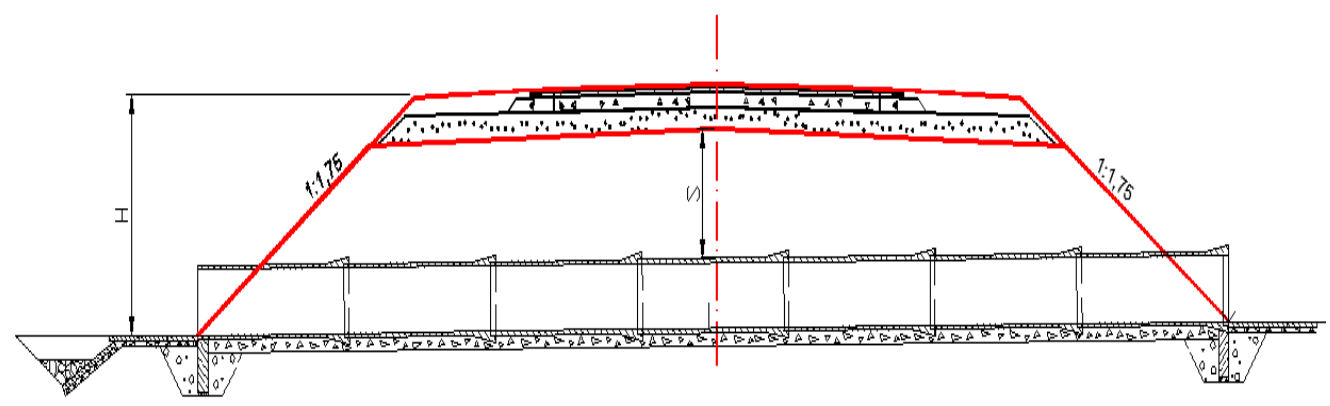

Figure 4. Variant of the cross profile for the appropriation of the height of the embankment above the artificial structures

As a result of this process, the opposite line of guiding marks is formed which becomes the sketch line of guiding marks after making a probable author's "edit". In some cases a sketch line of guiding marks is formed in the process of optimizing the position of the cross-section of a new pavement that ensures maintenance of the required thicknesses of strengthening the existing pavement and alignment of its cross down-grades.

If the geometric properties of the sketch line of guiding marks provided a safe and comfortable motion with the calculated speed, then this would be possible to stop because minimal costs would be required to implement and operate this solution.

The efficiency criterion of the solution of the problem for optimizating the project profile on the subsequent stage should reflect not the volumes or the cost of construction works in general, but only those additional volumes which are due to the inevitable deviations of the project line of the longitudinal profile which are necessary to represent its geometric properties in accordance with the established requirements.

In the considered problem it is accepted that the volumes of these "undeveloped" or "overfulfilled" works correlate with the total area of the figures formed by the project line and the sketch line of the guiding marks throughout the projected section that separated by the points of intersection of these lines. 
In order to take into account the circumstances that led to the position of the sketch line of guiding marks on those or other sections of the road, restrictions are also imposed, which imply the method of approaching the project line to the sketch line of guiding points.

It is quite obvious that the project line should not:

- To lower below the sketch line of the guiding marks on the flooded sections of the road or on the sections of repair or reconstruction in case of impossibility or impracticality of milling of the existing pavement;

- Not to exceed the sketch line of the guiding marks on the sections of intersections with the power line, with overpasses or with other communications.

In case of a clear tendency of the course of optimization to violate these conditions, a condition "not lower" or "not higher" are imposed on such sections.

These measures substantially limit the sphere of the permissible values of the parameters of the decision elements, so they should be resorted to only in an extreme case.

The best way to account for all the nuances of a projected object is to edit the sketch line of guiding marks, or to use weighting coefficients that established after analyzing the optimization results with the condition of "arbitrary" approaching it.

In this way, this multicriteria operation is reduced to a single-criterion, the direct task of which is expressed by the formula:

$$
W=(a, x),
$$

where: $W$ - the total area of all figures between the design line and the sketch line of the guide marks, calculated taking into account the given weighting coefficients; $x$ - a set of all elements of the current solution corresponding to a given set of conditions.

\section{Dynamic programming for finding the optimal design solution}

In spite of the simplicity of the chosen efficiency index $W$, an analytical description of its functional dependence from the large number and variety of parameters of the elements of the solution $\mathrm{x}$ is not possible, and also their imposed restrictions are not possible.

To solve the inverse problem of investigation of the given operation, the method of dynamic programming was most acceptable. In this case, it would be more correct or more accurate to call it a dynamic planning or design method.

Dynamic programming (or "dynamic planning") is a special method of optimization of solutions, specially adapted to the so-called "step-by-step" (or "multi-step") operations that decaying into $n$ sequential "steps" or "stages", each of which on its borders may have $m$ alternatives forming $m_{2}$ elements of the solution.

The given example of longitudinal profile optimization in the class of $G_{2}$-smooth functions describing each of the elements of the solution $x$ is ideally consistent with the condition of membership on the steps of the operation of its optimization by the method of dynamic programming.

But unlike natural membership on the steps of such actions as choosing the number of steps that can be broken down into a longitudinal profile, we have some freedom that can be used as an additional factor that increases the quality of design decisions (Credo-Dialogue, 2019; Fedotov \& Pospelov, 2007).

In previously developed methods of "anchor points", "boundary iterations", "nonlinear programming" or "gradient projection", such "membership" on the steps did not explicitly foresee (Fedotov \& Pospelov, 2007).

In the other case, the methods of their solution would be called "dynamic programming" and their solutions would not be limited to the class of functions $G_{0}$ - order of smoothness with all the disadvantages.

These disadvantages are that the piecewise linear description of the solutions obtained by these methods is inconsistent with current regulatory requirements or with modern automated road design and construction technologies.

The problem of further approximation of these solutions in the class $G_{1}$ - smooth functions did not find a reliable and justified solution.

The alternative to sorting out all the possible options is to divide this task into separate steps and build such a process of purposeful, organized search for a solution of steps that will have clear advantages over a naive "blind" search. In dynamic programming, this process is organized by the principle that at each current step the optimal element of the solution is chosen so that the cost of all remaining steps is minimal. Adherence to this principle reduces the dimension of the problem and makes it commensurate with the number of alternative parameters of elementary decisions.

In the context of this task, the experience of the researcher is manifested in:

-Development of component polynomial cubic V_Spline and algorithms for optimization of their parameters in composition $G_{2}$ - smooth polyline of longitudinal profiles;

-Overcoming the "curse of the mass-dimensionality" by means of the "drifting" corridor of decision elements with variable parameters;

- Development of technology of sequential optimization of the profile in classes $G_{1}$ and $G_{2}-$ smooth functions (Fedotov \& Pospelov, 2007; Velychko \& Fylyppov, 2016). 
Figures 5-7 illustrate the results of these solutions.

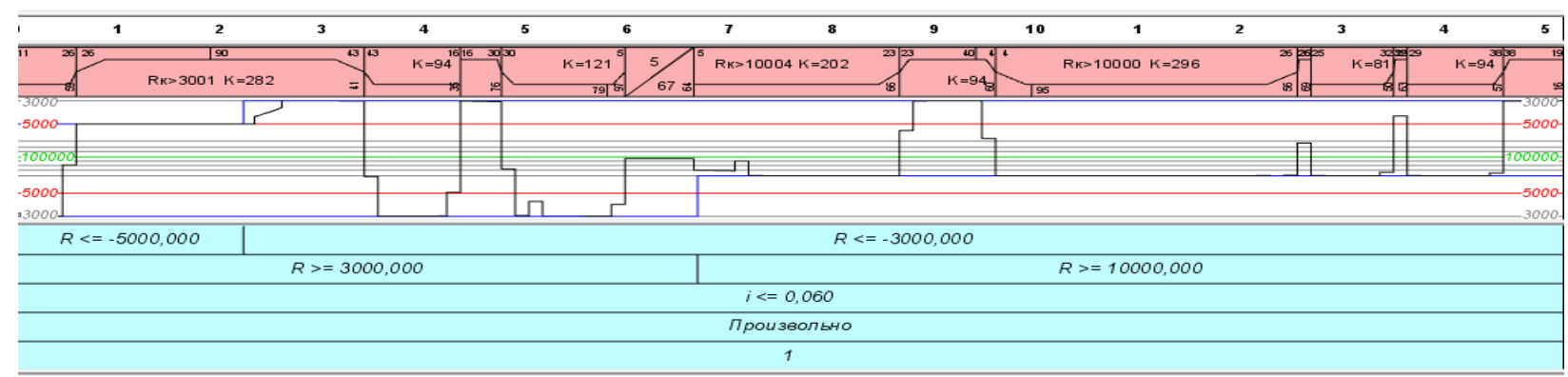

Figure 5. Example of optimization of a section of a road in class $G_{1}-$ smooth functions

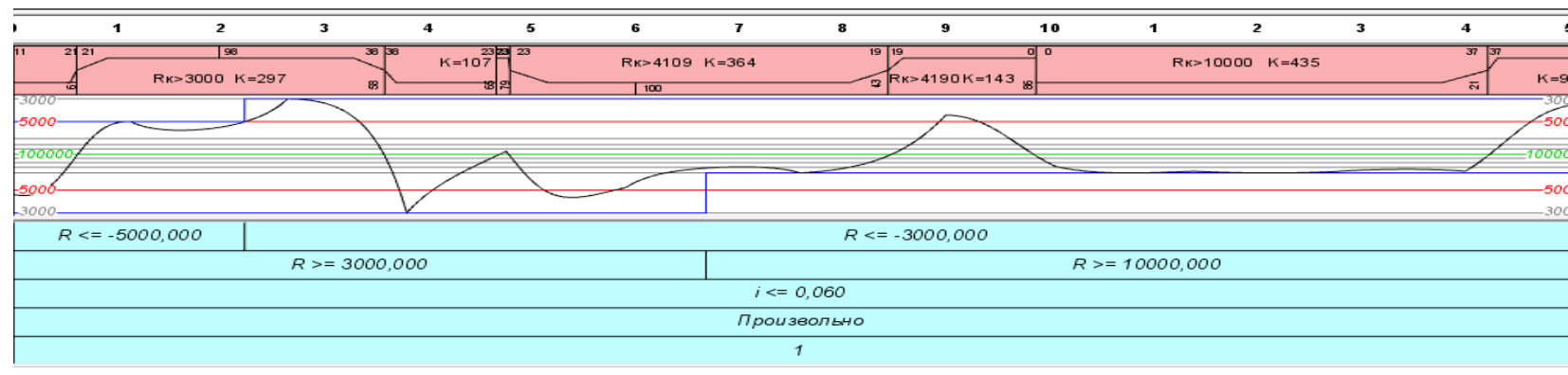

Figure 6. Example of optimization of a section of a road in class $G_{2}-$ smooth functions

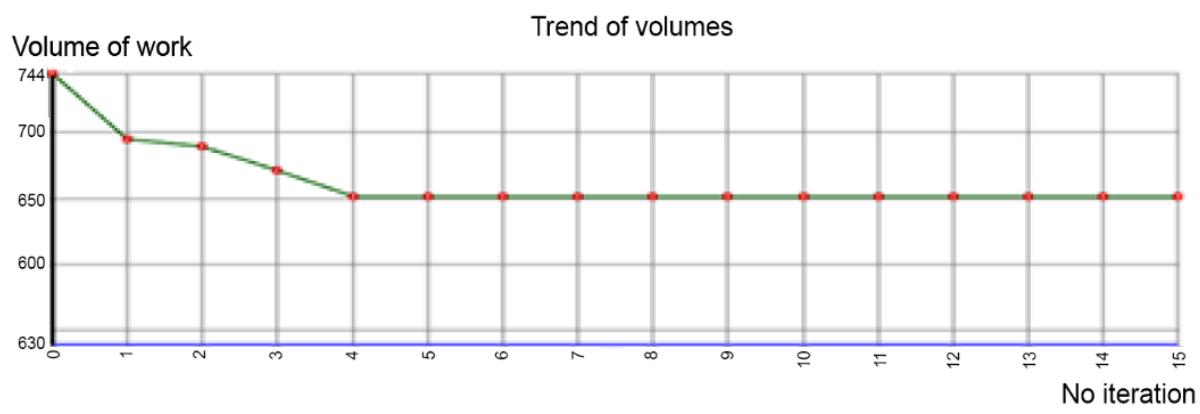

Figure 7. Trend of job content in the process of optimization of a section of a path in class $G_{2}$ - smooth functions

\section{Conclusions}

Based on the analysis of the existing methodological principles of finding the optimal design solution, we can draw the following conclusions:

1. The analysis of the accumulated practice of applying the method of "dynamic programming" while optimizing the longitudinal profile in the "drifting" corridor with variable parameters of the elements of the solution testifies to its reliable and stable operation.

This is confirmed by the projects of new construction, repair and reconstruction of many hundreds of sections of the connection paths of the Union of Independent States, the total length of which is thousands of kilometers.

The most technically and economically efficient application of this method is manifested by the most massive types of design work to repair or reconstruct existing communication paths.

Components of polynomial cubic V Spline and algorithms for optimization of their parameters in composition $G_{2}$ - smooth polylines of longitudinal profiles provide high transport and operational qualities of the arrangement of pavements at minimal volumes of alignment and milling of existing pavements.

Geometric accuracy, detail and quality of these solutions are consistent with the analogous indexes of modern research that carried out with the application of high-precision methods of laser scanning, and also with the capabilities of modern $3 D$-systems of the automated control of road construction machines which ensure high accuracy of construction and repair of roads on their digital models. 
2. The analysis of these and other types of work confirms the importance of compliance as general principles:

- Choice of indicators for effectiveness of decisions;

- Comparable accuracy and detail of applied mathematical models;

- Their ability to reflect the most important features of the simulated phenomenon, and also all the essential factors on which the success of the operation under investigation depends.

3. Particularly noteworthy is the inevitability of participation, and also the high role of the applied specialist, appropriate for:

- Statement of the operation research task;

- Selection of mathematical models and their parameters;

- Comprehending the results of the calculation of making final decisions.

4. As the practice of working, development and implementation of information technologies shows, the functions of the applied specialist are not abolished, but simply shifted from one elementary level to another, higher. Even if the creation of control algorithms or the choice of one of its possible variants, is also a very appropriate solution, which lies with specialist in the relevant branch of knowledge.

\section{References}

Autodesk. (2020). AutoCAD Civil 3D. 2020. New features. https://www.autodesk.ru/products/civil-3d/new-features

Chepel, E. (2015). AutoCAD Civil 3D 2014. Oficial'nyj uchebnyj kurs [AutoCAD Civil 3D 2014. Official training course]. DMK Press.

Credo-Dialogue. (2019). Software products of the CREDO complex. https://credo-dialogue.ru/produkty.html

Fedotov, H. A., \& Pospelov, P. I. (2007). Spravochnaja jenciklopedija dorozhnika. Tom 5: Proektirovanie avtomobil'nyh dorog [Reference encyclopedia of the road builder. Volume 5: Road design]. Informavtodor.

Gosstandart. (2006). Avtomobil'nye dorogi. Normy proektirovanija [Highways. Design standards] (TKP 45-3.03-19-2006). Minstrojarhitektury.

Labenko, D. P., \& Timonin, V. O. (2012). Geoinformacijni sistemi [Geoinformation systems]. HNADU.

Ministerstvo regional'nogo rozvitku, budivnictva ta zhitlovo-komunal'nogo gospodarstva Ukraini. (2015). Avtomobil'ni dorogi. Chastina I. Proektuvannja Chastina II. Budivnictvo [Highways. Part I. Design part II. Construction] (DBN B.2.3-4:2015). Minregion Ukraini.

Ministerstvo regional'nogo rozvitku, budivnictva ta zhitlovo-komunal'nogo gospodarstva Ukraini. (2008). Derzhavni budivel'ni normi Ukraini. Sporudi transportu zaliznichnoi kolii $1520 \mathrm{~mm}$ [State building codes of Ukraine. Railway track construction $1520 \mathrm{~mm}$ ] (DBN-B.2.33-19-2008). Minregion Ukraini.

Rosavtodor. (2003). Analiz norm proektirovanija polotna avtomobil'nyh dorog zarubezhnyh stran na primere poslednih norm $i$ pravil Federativnoj Respubliki Germanii. Prilozhenie I, II [Analysis of the norms for designing the roadbed of foreign countries on the example of the latest norms and rules of the Federal Republic of Germany. Appendix I, II] (RAS-Q). Retrieved October 1, 2008, from http://www.gosthelp.ru/text/Analiznormproektirovaniya.html

Sivovolov, I., \& Ivanov, I. (2008). Primenenie programmnogo kompleksa MX v proektirovanii gorodskih ulic i dorog [Application of the MX software package in the design of city streets and roads]. Retrieved April 20, 2010, from https://sapr.ru/article/7778

Velychko, H. V., \& Fylyppov, V. V. (2016). Sravnitel'nye svojstva perehodnyh krivyh [Comparative properties of transition curves]. Retrieved September 14, 2016, from https://docplayer.ru/52907323-Sravnitelnye-svoystva-perehodnyh-krivyh.html

Zatserkovnyi, V. I., Burachek, V. H., Zhelezniak, O. O., \& Tereshchenko, A. O. (2014). Geoinformacijni sistemi i bazi danih [Geoinformation systems and databases]. NDU im. M. Gogolja. 